\title{
Digital Fabrication of Contemporary Structures in Architectural Design Optimization
}

\author{
Anna Stefańska ${ }^{1}$ and Saurav Dixit ${ }^{2}$
}

1 Department of Structure, Design, Construction and Technical Infrastructure, Faculty of Architecture, Warsaw

University of Technology, Poland, anna.stefanska2@pw.edu.pl

2 RICS School of Built Environment, Amity University Noida, India, sauravarambol@gmail.com

\begin{abstract}
Trends in contemporary architecture are constantly changing the quality of engineering solutions through broadly understood optimization. The designers, as never before, are facing the possibility to adjust the material and manufacturing technology to desired aesthetic outcomes, by not only the material usage but also the self-organization of the optimization of the structure. The development of modern computational software and the ability to modeling structural forms in non-Euclidean geometry while using algorithms lead designers to new fields of designing and constructing. Parameterization of modeling tools and processes caused an increase in interest in bionic and biomimetic inspirations. It is expressed by imitation of the structure and behavior of living organisms. Such actions enabled the implementation of ideas as forms follow energy and forms follow forces. Analysis of the morphology of structural forms as well as generative modeling based on logical patterns taken from Nature are one of the contemporary tools of designing. Nowadays, the development of building technologies is strongly supported by digital techniques of manufacturing building elements, which has a significant impact on the architectural detail shaping. Geometrically complex forms are generated as non-modular elements; due to the rapid growth of digital fabrication (components with different shapes are made individually - cut out by CNC machine tools, printed, cast). with outstanding precision). A vital element of new technologies development is the search for new materials and the improvement of manufacturing methods at the same time. The article presents new tools and methods for the optimization of structural elements on selected examples.
\end{abstract}

(c) 2020 The Authors. Published by Budapest University of Technology and Economics \& Diamond Congress Ltd Peer-review under responsibility of the Scientific Committee of the Creative Construction Conference 2020.

Keywords: Architectural Design Optimization, digital fabrication, fabrication, generative design

\section{Introduction}

Trends in contemporary architecture are constantly changing the quality of engineering solutions through the broadly understood optimization process. The designers, as never before, are facing the possibility to adjust the material and manufacturing technology to desired aesthetic outcomes [1]. The information technologies drastically changed the designing process giving the ability to optimize not only the material usage but also the self-organization of the structures [2]. In the process of evolutionary design, which is a part of Architectural Design Optimization, the main focus is not only on the architectural design phase but also on optimizing the construction and object management phases. The 21 -century is characterized in Sustainable Development, which stresses that, among others, the AEC sector should reduce energy consumption and greenhouse gas emission. The optimization of the designing process in AEC is still inefficient because each discipline is optimizing its part of the project without a global overview of the whole undertaking [2] [3]. Implementing artificial intelligence (Al) into the designing process accelerated cooperation in the AEC sector since the case studies are still conducted on prototypes of small scale instead of professional practice systems [4]. 
In contemporary interdisciplinary designing, there is a noticeable approach in prototyping in architectural scale. The ability to create a complex geometry of free-form buildings requires not only the knowledge of designing software (CAD) but also understanding of the manufacturing conditions and restrictions (CAM). Contemporary prototyping requires designers to develop an idea to ready product methodology of working and fully understanding material properties. The form follows material statement is nowadays an essential factor of fabrication. The advancing digitalization of designing and fabrication tools faces a slow change in designing awareness. For the first time in history, designers face no strict regimes while using specific construction technologies. Digital fabrication helps to achieve a unique architecture with standard materials such as steel or concrete [5]. In the middle of the 20th-century (1947), Mies van der Rohe referring to a minimalist style, said a maxim 'Less is more.' This time in architectural design is characterized by the awareness of cost and time reduction achieved by mass production of identical elements. Especially visible in engineering sectors such as car fabrication and assembling of unified elements were factors economic prosperity. In the construction industry, the catalogs of ready-made, available at a place in warehouse building parts become available to quick assembly. Available now, the revolution of choices [6] exposes designers to limitless possibilities of materials, technology, manufacturing. New materials and technics of assembly are being invented. No longer, the cost optimization is connected with unified, identical structural or architectural elements. The Post-Fordism era thanks to the access to digital fabrication and rapid prototyping, allows designing with not seen before precision. Access to digital fabrication in the interdisciplinary designing, where architects, structural designers, material engineers can design a new methodology of creating unique solutions, based on the needs of the building, not on the available or unified materials and their geometries. The best example can be here the brick, which has a standardized dimension in comparison to the $3 \mathrm{~d}$ printed clay element adjusted to the exact needs of the project.

Nowadays, the development of building technologies is strongly supported by digital techniques of manufacturing building elements, which has a significant impact on the shaping of architectural details. Geometrically complex forms are generated as non-modular elements; due to the rapid growth of conventional fabrication (individual components are made individually - cut out by CNC machine tools, printed, cast). The new language was needed, which does not use traditional technical drawing. An example can be file-to-factory, the communication between humans and machines in prototyping. This method, instead of leading the designing process, adapt out results to available technology [7]. The main advantage of this type of rapid prototyping is the ability to sustain the perfect outcomes-the the final product of each individual element. No more the repetitive, utilized elements guarantee the exact manufacture dimensions. As an example of different methods of manufacturing technologies using the same material, which can be a clay is formative and additive digital fabrications. By forming materials, robots or drones are used to assemble brick following a predesigned pattern, while in 3D printing, a clay is printed in layers in order to obtain the required shape [8].

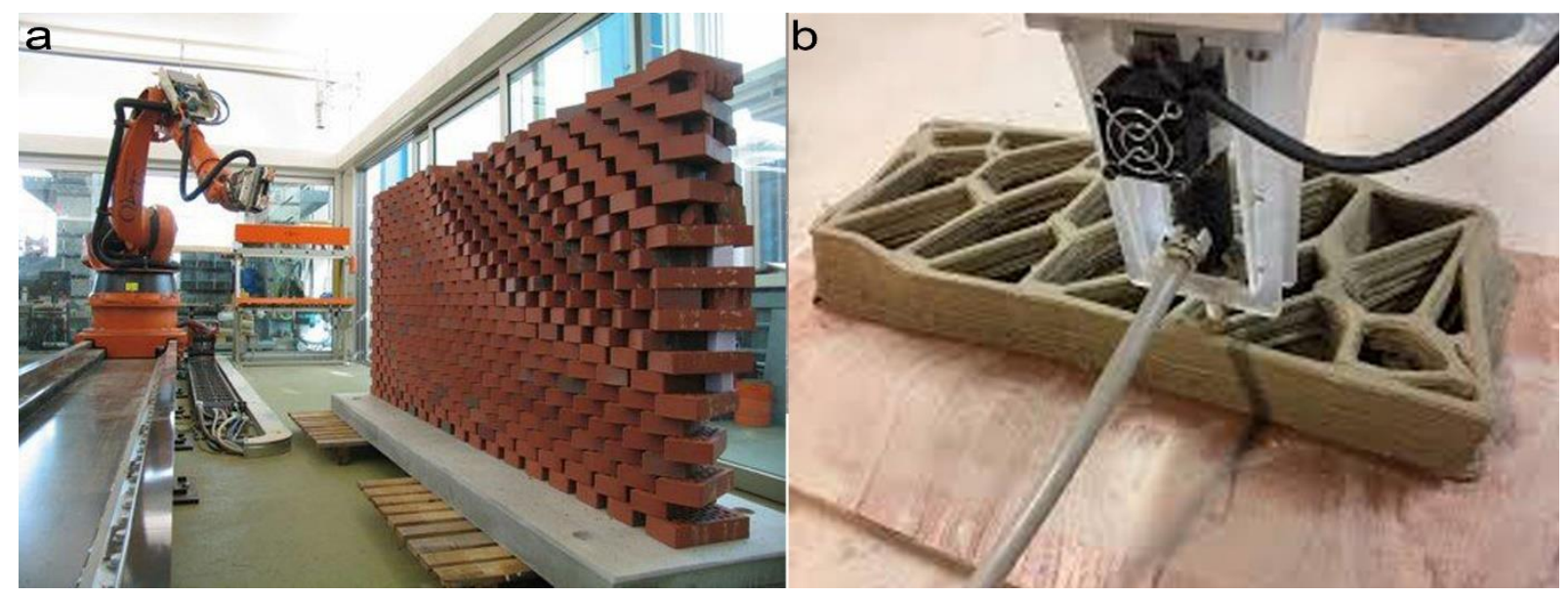

Fig. 1. Examples of fabrication methods using different approach using clay material: (a) Structural Oscillations, Installation at the $11^{\text {th }}$ Venice Architectural Biennale, by Gramazio \&Kohler Research, ETH Zurich, (b) 3D printing execution [8] 


\section{Literature review}

The complexity of contemporary designs, lead to the 'more is different' statement [9]. The role of the designers in the creative designing practice changed, from designing exact geometries, based on available element cross-sections, to controlling the process of designing rules. It is visible in the new sustainable fabrication methods, like FiDU (ger. Freie Innen Druck Umformung), which stands for Free Inner Pressure Forming. This method allows receiving lightweight structures with a high-stress capacity, as well as the size of the file needed in file-to-factor manufacture technology.

Development of modern computational software and the ability to modeling structural forms in nonEuclidean geometry while using algorithms lead designers to new fields of designing and constructing. Parameterization of modeling tools and processes caused an increase in interest in bionics and biomimetics. It is expressed by imitation of the structure and behavior of living organisms. Such actions enabled the implementation of ideas as forms follow energy and forms follow forces. Analysis of the morphology of structural forms as well as generative modeling based on logical patterns taken from Nature are one of the contemporary tools of rational design. Not only in the context of minimizing material usage but what is more important, in the self-organization of structural elements to attain force equilibrium in structures.

The interrelation between shape, material, and behavior of structures found in Nature becomes a base of new methods of optimization. Biomimetic inspirations are the main factor of the designing process, where the properties of selected materials, structural behavior as well as manufacturing technologies influence the early stage of designing and, therefore, the structural optimization process [10] [11]. The integration of tools that help to optimize the construction process under human-machine collaboration is continuously invented [12]. An example of an interdisciplinary tool where material properties are one of the main factors of optimizing the final architectural form is a Material-based Integrated Computational Design Model (MICD-m), where parametric modeling environment was used [13]. The ability to create a new method of fabrication and the understanding of the material which designers use nowadays lead to the creation of a new language and a platform of communication, which goes far beyond the complexity of the form [14] to synthesis and sustainable performance in order to achieve the minimization of costs and the consumption of natural resources [15].

\section{Discussion}

A vital element of manufacturing development is the search for new materials and the improvement of technologies such as digital machines supporting manufacturing processes. The control of the CAD-CAM prototyping is based on multicriteria optimization [16]. It also helps in incorporating variable parameters into the design, such as structure modeling, shapes, fabrication method, material properties, but also material and structure behavior, lightning, heat, humidity, or air movement [17]. The most significant factor of digital fabrication and prototyping is the availability of fabrication solutions, as well as the supervising of the assembling process and correcting errors (if any occurs during fabrication). 


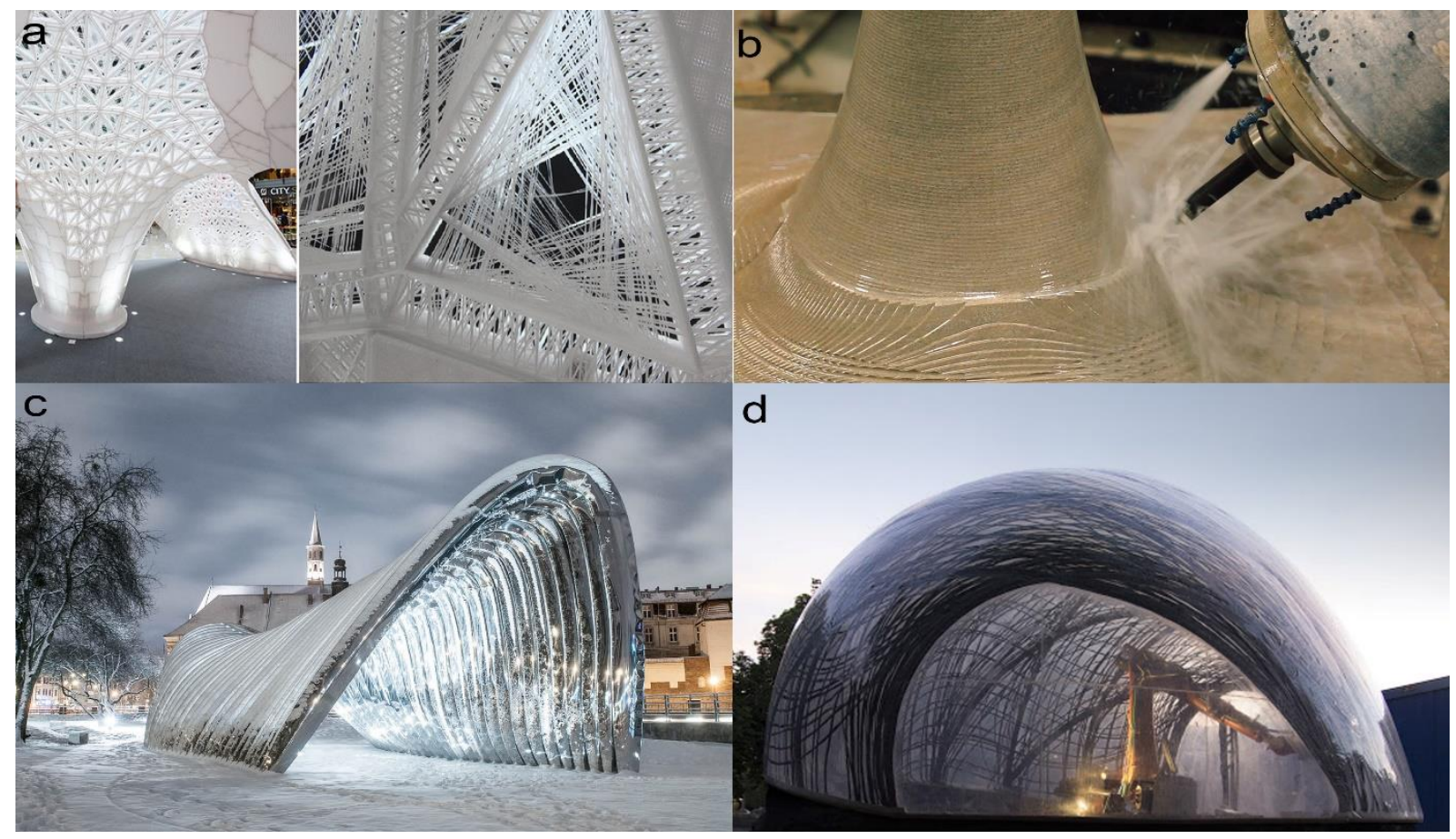

Fig. 2. Basic methods of fabrication in small scale object: (a)additive technology- the Vulcano Pavilion, (b)subtraction technology-The Autodesk Pavilion, (c)formative technology- Nawa Pavilion, (d) formative technology-ICD-ITKE Research Pavilion

The turn from $\mathrm{NC}($ Numerical Control) to $\mathrm{CNC}(\mathrm{Computer}$ Numerical Control) devices improved the prototyping and fabrication development. The two main methods of fabrication are Subtraction and Addition. In the first method, robots, lasers, streams of water, or plasma as we as more traditional tools as cutting blades might be used. Basing of the available type of the machine, 2D, and 3D objects of architectural scale can be obtained. However, these machines are limited to the cutting area or machine arm length. Up to 21-century in additive methods, only small scale objects could be made. The leading technology of additive methods is 3D printing. Currently, massive scale concrete printers are available to print, for example, a concrete building element, such as beams, trusses, as well as whole buildings. The most basic printing materials are plastic, clay, concrete, or steel. The significant area of research is based on the new bio-engineering material, such as biodegradable timber composites or technologies of 3D bioprinting. The combination of those which use machines to assembly the undertake without human interaction. In this method, robots, as well as drones or any other computer-controlled tools, can be used. This method is by far one of the most challenging for designers, not only they have to design the geometry(CAD), precisely understand the materials and machines properties (CAM), but also set the exact algorithm for assembling. This method is mostly accompanied by generative design as well as computational methods of manufacturing, give designers illusory feeling that they replace his thought process. In fact, by following his algorithmic instructions, they are indicators of the quality of designers' knowledge and creativity [18] [19]. In this sense, digital fabrication, in combination with generative design, can be considered as a synthesis of logic thinking, knowledge, which combines technical and human needs solutions and what is the essential freedom of design [20].

\section{References}

[1] B. Leibinger, An Atlas of Fabrication, London: Architectural Associacion Publications, 2009 ISBN 978-1902902753.

[2] E. Pantazis and D. J. Gerber, Beyond geometric complexity: a criterial rewiew of complexity theory and how it relates to architecture engineering and constructuin, Architectural Science Review 62(5), p. 371-388, 2019. https://doi.org/10.1080/00038628.2019.1659750

[3] S. Dixit and S. Kaaraayaarthi, An Empirical Study of Major Factors Affecting Productivity of Construction Projects, Emerging Trends in Civil Engineering, p. 121-129, 2020. https://doi.org/10.1007/978-981-15-1404-3_12

[4] M. Halfawy and T. Froese, Building Integrated Architecture/Engineering/Construction Systems Using Smart Objects: Methodology and Implementation, Journal of Computing in Civil Engineering, vol. 19(2), 2005. https://doi.org/10.1061/(asce)08873801(2005)19:2(172) 
[5] A. Kaiser, M. Larsson and U. A. Girhammar, From file to factory: Innovative design solutons for multi-storey timber buildings applied to project Zembla in Kalmar, Sweeden, Frontiers of Architectural Research 8(1), p.1-16, 2018. https://doi.org/10.1016/j.foar.2018.12.001

[6] B. Leibinger, New Structuralism: Design, Engineering and Architectural Technologies Vol.80(4), pp.14-23, vol. 80(4), R. Oxman and R. Oxman, Eds., Architectural Design, 2010. https://doi.org/10.1002/ad.1101

[7] A. Papamanolis, V. Geropanta, Information Technologies in Architectural Pedagogy: from "Tool" to a "Comprehensive Educational Strategy", Emerging Trends in Education 1(1), 2018. https://doi.org/10.19136/etie.a1n1.2788

[8] O. Kontovourkis, G. Tryfonos and C. Georgiou, "Robotic additive manufacturing (RAM) with clay usinng topology optimization principles for toolpath planning:the example of a building element," Architectural Science Review 63(2), p. 105-118, 2019. https://doi.org/10.1080/00038628.2019.1620170

[9] P. W. Anderson, "More Is Different," Science, no. 177(4047), pp. 393-396, 04 August 1972.

[10] H. Pottmann, Architectural Geometry and Fabrication-Aware Design, Nexus Netw J, vol. 15(2), pp. 195-208, 2013. https://doi.org/10.1007/s00004-013-0149-5

[11] M. Tamke, M. Burry, P. Ayres, J. Burry and M. R. Thomsen, Design Environments for Material Performance, in Computational Design Modelling, C. Gengnagel, A. Kilian, N. Palz and F. Scheurer, Eds., Berlin, SpringerLink Books, p. 309-318, 2011. https://doi.org/10.1007/978-3-642-23435-4_35

[12] P. Yuan and C. Yan, Collaborative Networks of Robotic Construction, Architectural Design, vol. 90(2), pp. 74-81, 2020. https://doi.org/10.1002/ad.2549

[13] S. Yazici és L. Tanacan, A study towards interdisciplinary research: a Material-based Integrated Computational Design Model MICDm) in architecture, Architectural Science Review 61(1-2), p. 68-82, 2018. https://doi.org/10.1080/00038628.2017.1416575

[14] M. Male-Alemany, J. Ameijde van and V. Vina, (Fab)bots customised robotic devices for design \& fabrication, in Fabricate 2011: Making Digital Architecture, London, UCL Press, pp. 39-46, 2017. https://doi.org/10.2307/j.ctt1tp3c6d.11

[15] D. Coupek, D. Kovaleva, H. Christof, K.-H. Wurst, A. Verl, W. Sobek, W. Haase, G. T. Gresser and A. Lechler, Fabrication of Biomimetic and Biologically Inspired (Modular) Structures for Use in the Construction Industry, in Biomimetic Research for Architecture and Building Construction, Cham, Springer International Publishing, p. 319-340, 2016. https://doi.org/10.1007/978-3319-46374-2_16

[16] M. Michael, From Control to Design : Parametric/Algorithmic Architecture, T. Sakamoto, A. Ferre and M. Kubo, Eds., New York, Barcelona: ActarD Inc, 2008. ISBN 978-84-96540-79-8

[17] M. Burry and J. Burry, Prototyping for architects, London: Thames\&Hudson, 2016. ISBN 978-0-500-29249-5

[18] J. S. Gero, Computational Models of Innovative and Creative Design Processes, Technological Forecasting and Social Change, pp. 183-196, 2000. https://doi.org/10.1016/s0040-1625(99)00105-5

[19] W. Bonenberg, M. Giedrowicz and K. Radziszewski, Współczesne Projektowanie Parametryczne (eng. Contemporary Parametric Design), Poznań: Wydawnictwo Politechniki Poznańskiej, 2019. ISBN 978-83-7775-548-8

[20] T. Kotnik, Research culture in architecture, Cross-Disciplinary Collaboration, C. Leopold, C. Robeller and U. Weber, Eds., Berlin/Boston: Birkhauser, 2020, pp. 183-192. ISBN 978-3-0356-2014-6 